\title{
Sem Evaluation of Eroded Dental Enamel After The Use of Different Types of Fluoride Tooth Pastes (In Vitro)
}

\author{
Denkaova N. ${ }^{1}$, Iljovska S. ${ }^{2}$ \\ ${ }^{1}$ Department Of Pediatric Dentistry, University Goce Delcev In Stip, Macedonia \\ ${ }^{2}$ Deparment Of Pediatric Dentistry, Ss. Cyril And Methodius University In Skopje, Macedonia
}

\begin{abstract}
Material And Methodology: In the study we included 5 different samples of premolars which were alternatively exposed to $4 \mathrm{pH}$ erosive cycles during the day, with a duration of 90 seconds, in 0,1\% citric acid mixed with artificial saliva in a period of 5 days. In between the intervals of exposure, the samples were washed with deionized water (10 seconds) and were transferred into artificial saliva $\left(\mathrm{pH} 6.8,30 \mathrm{ml} / 37^{\circ} \mathrm{C}\right)$, which was renewed every day.

With the aim to assess the efficiency of the fluoride agents on the progression of the erosion, we included 5 agents with which we treated the enamel samples: Parodontax toothpase (without fluoride-control), Crest toothpaste (NaF-1500 ppm F, pH 6,9, Procter \& Gamble); White Glo (5,63\% F, pH 8,0),Fluoride solution (NaF )1450 ppm F);TiF4 (1450 ppm F).

The procedure was repeated twice daily, after the first and the last erosive challenge, and after the first and forth day, the samples were examined with an electric microscope.

Results: The results for the morphological changes of the dental enamel samples, after the first and the forth erosive cycle showed that after the first erosive cycle, the remineralisation effect did not show significant morphological changes despite which fluoride agent was used for remineralisation (Crest, Parodontax, White Glo, Tif4, Fluoride Solution), opposed to the forth day where the best preventive effect was seen from Tif4, Fluoride Solution.

Conclusion: The results we got from our study, suggest that this topic should be studied further in more complex invivo conditions and our results should be confirmed.
\end{abstract}

Keywords: dental erosions, SEM evaluation, Crest, Parodontax, White Glo ,Tif4, Fluoride Solution

\section{Introduction}

Dental erosion is defined as progressive non-carious condition of the teeth characterized with irreversible pathological loss of the surface of dental tissue as a result of chemical processes and does not include bacterial infections. Over the last two decades, dental erosion has become a significant clinical problem. ${ }^{1}$

The onset of erosion of the dental enamel is a subject of investigation since the beginning of the $19^{\text {th }}$ century ${ }^{2}$ and from then, the incidence and prevalence of dental erosions are becoming a subject of interest in many studies carried out throughout the world. ${ }^{3}$

The dental erosions besides the fact that they can be identified clinically, also have specific histological changes of the hard dental tissues, which in the early phases can change the mechanical and physical characteristics of the teeth as a result of the loss of minerals, most commonly due to the affects of acids, which acids effect the dental enamel and dentine with an unequal intensity. The ability of the acids to cause loss of minerals from the enamel or from the dentine according to Graubart ${ }^{4}$ and Featherstone ${ }^{5}$ depends from the buffering capacity of the saliva, which in fact is connected to the concentration of acids in drinks and food which we consume on a daily basis. As a result, there is a faster demineralization and release of mineral salts, and also the formation of erosive surfaces on the teeth.

Bartlett и Dugmore ${ }^{6}$ mentioned that in enamel, the lesion primarily develops in the prism sheath areas, followed by dissolution of prism cores. Eventually, the interprismatic areas are also affected. Bulk mineral is centripetally etched away in enamel erosion leaving a partly demineralized softened surface layer, which is prone to mineral deposits after topical fluoride application.

Processes in the dentin describes Amaechi et.al. ${ }^{7}$, which emphasize that erosive demineralization results in the exposure of an outer layer of fully demineralized organic matrix followed by a partly demineralized zone until the sound inner dentin is reached ${ }^{55}$. There are several physiological factors that may modify the erosive process both ways, i.e. they may either protect against erosion or increase the degree of erosion. These include saliva, tooth composition and structure, dental anatomy and occlusion, anatomy of soft tissues in relation to teeth, and physiological movements like swallowing.

However for these changes to happen, numerous physiological factors can affect in which direction the erosive process will go, more precisely, they can either stop the occurrence of dental erosions or they can 
worsen the clinical presentation of the erosion. From the physiological factors we can accent the composition of the saliva, the composition, structure and anatomy of the teeth and the soft tissues, the type of occlusion and similar.

The use of fluoride as a therapy is used more than 50 years and it is an imperative in the preventive strategies against dental caries. ${ }^{9}$ The remineralisation of the dental enamel is helped by the protective factors of the oral cavity and by the additional use of fluoride agents and bioavailable calcium and phosphates, which are used locally. ${ }^{10}$ The best results are achieved by affecting the tooth surface or the plaque, and with that mechanism we can arouse the remineralisation of the teeth, especially in the early phase of the carious lesion or with those means we can decrease the enamel solubility. ${ }^{11}$

The results from numerous studies, show that the prophylactic effect of the toothpastes are directly dependent with the concentration of the ionic or the initial fluoride, which is released when the toothpaste is used in the oral cavity. Also of great importance are the labial bonded fluorides which with hydrolysis release free ions of fluoride. ${ }^{12}$

The use of toothpastes with fluoride is the simplest way to prevent dental caries and due to that fact, the prevalence of dental caries, in the developed countries is drastically decreased. A problem arouses while dosing the fluoride in the toothpastes, for which problem many experts conclude that the dose should be between 1000 and $1100 \mathrm{ppm} \mathrm{F}(1-1.1 \mathrm{mg} / \mathrm{g}){ }^{13,14,15}$

The aim of our study is to assess the efficiency of the toothpastes with different concentrations of fluorides in eroded surfaces of dental enamel in teeth with different erosive cycles. (in vitro)

\section{Materials and methods}

In the study we included 5 extracted intact premolars from healthy patients at the age from 30 to 50 years.

\subsection{Experimental studies $\mathbf{F}$ (in vitro)}

\subsubsection{Preparation of the samples}

The preparation of the enamel samples from teeth, was done with the use of a Cavo micro motor, a Superflex TURBO 505.504.160 mill, with a low speed of $25.000 \mathrm{rpm}$ next to the cement-enamel border from the labial and lingual surfaces, with dimensions of the samples of $4 \mathrm{~mm} \times 4 \mathrm{~mm} \times 3 \mathrm{~mm}$. The samples then were polished with silicium carbid disks - Universal Polishers PO502 with a low speed of $15.000 \mathrm{rpm}$. The samples were then cleaned with an ultrasound device and with deionized water in the duration of 5 minutes. next phase.

The prepared enamel samples were kept in a solution of $0.1 \%$ timol at a temperature of $4^{\circ} \mathrm{C}$ until the

The following phase consisted of coating $2 / 3$ of the surface of the samples with red nail polish, all with the aim to make a surface of the enamel which will be used as a control, which surface will be left without any treatment. (Pic. 1)

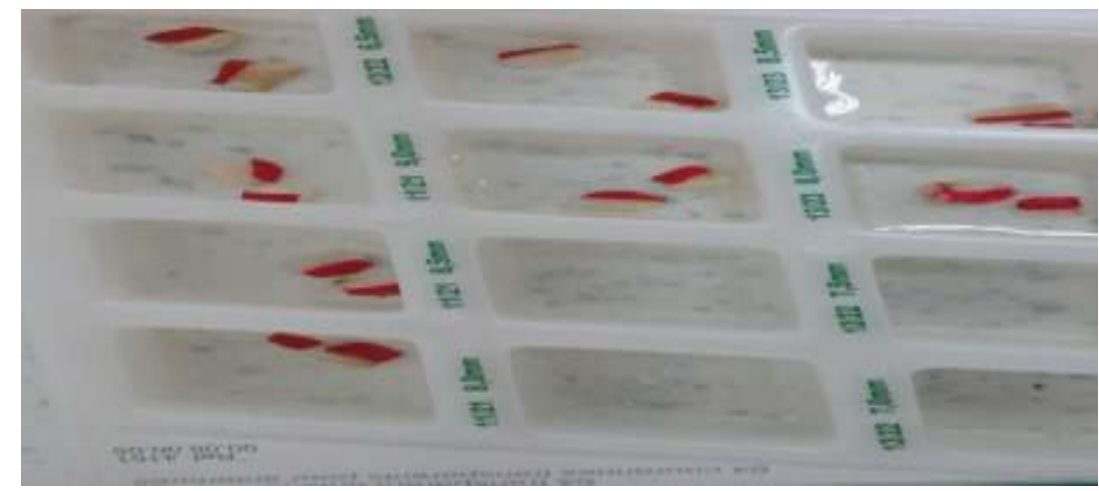

Picture 1

The finished samples were stored in artificial saliva $(\mathrm{NaCl}-0,50 \mathrm{~g} / \mathrm{l}-1 \mathrm{NaHCO} 3-4,30 \mathrm{~g} / \mathrm{l}-1 \mathrm{NaNO} 3$ $-0,03 \mathrm{~g} / \mathrm{l}-1 \mathrm{KCL} 0,20 \mathrm{~g} / \mathrm{l}-1$ ) with a $\mathrm{pH}$ of 6.8 which saliva was prepared at the Faculty for veterinary medicine of UKIM in Skopje.

The samples were kept at least 24 hours at a temperature of $37^{\circ} \mathrm{C}$ so they do not dehydrate until the experiment begins.

\subsubsection{Erosive cycles and experimental groups for analysis with $F$ (in vitro)}

The procedure was cyclic, and the samples were alternatively exposed to $\mathrm{pH}$ erosive cycles, 4 times during the day with a duration of 90 seconds, in $0,1 \%$ citric acid mixed with artificial saliva in a period of 5 
days. In between the intervals of exposure the samples were washed with deionized water (10 seconds) and were transferred into artificial saliva $\left(\mathrm{pH} 6.8,30 \mathrm{ml} / 37^{\circ} \mathrm{C}\right)$, which was renewed every day. The same procedure for demineralization was repeated in 5 erosion cycles, every day during 5 days.

With the goal to assess the efficiency of the fluoride agent on the progression of the erosion, we included 5 agents with which the samples of enamel were treated : Paradontax toothpaste (without fluoride), Crest toothpaste (NaF-1500 ppm F, pH 6,9, Procter \& Gamble); White Glo (5,63\% F, pH 8,0), Fluoride solution (NaF (1450 ppm F);TiF4 (1450 ppm F) .

The procedure was repeated 2 times daily, after the first and the last erosive challenge and then the prepared samples were treated with one of the agents with fluoride and with Paradontax toothpaste together with deionized water $(0.5 \mathrm{ml})$ in order to evade friction, in a time frame of 20 seconds.

\subsubsection{Scan electronic microscopy (SEM)}

The morphological changes of the dental enamel and the histological differences between the erosive cycles caused in vivo and the treatment with fluoride with different types of toothpastes were detected with a scan electronic microscope in the Faculty of Agriculture,University of Goce Delcev in Stip. (pic. 2,3,4,5,)
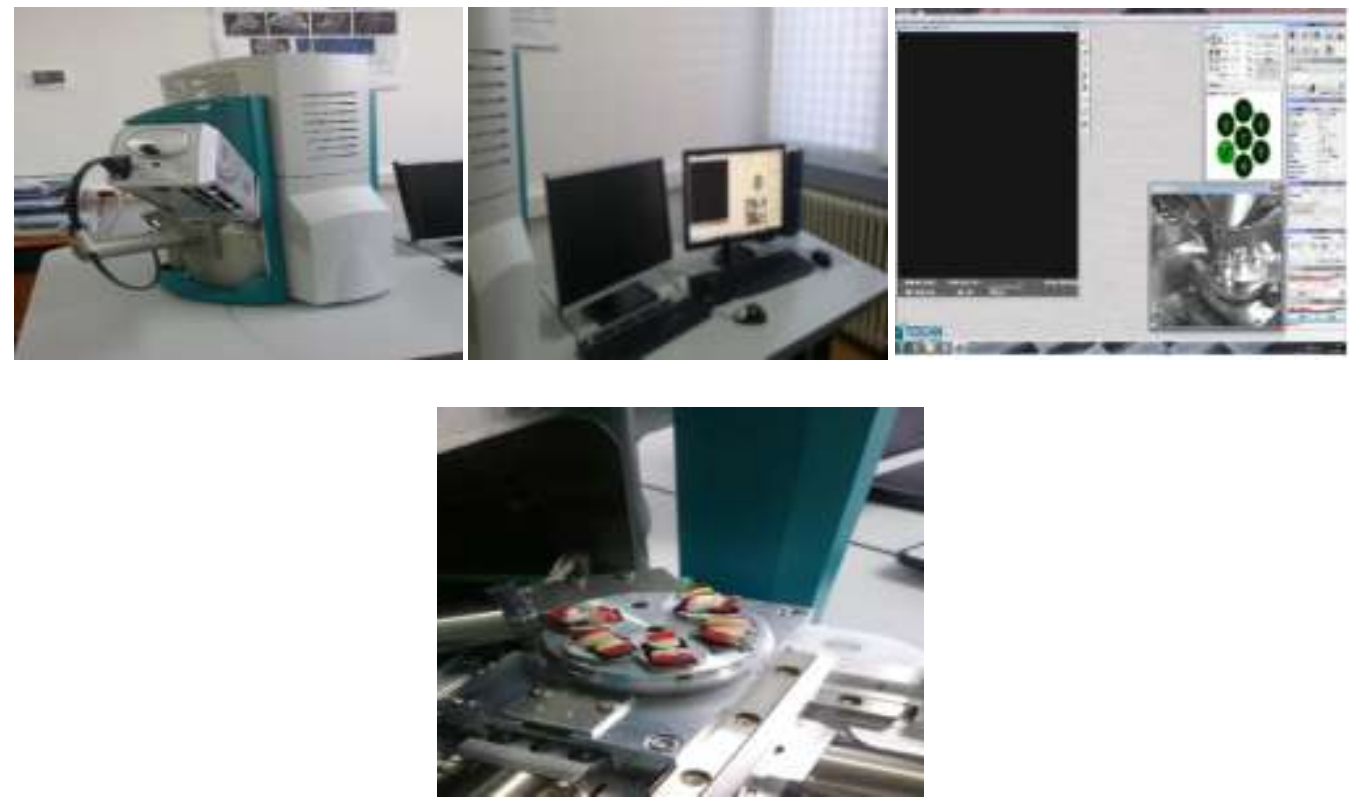

Picture 2,3,4,5 (Scan electronic microscope)

\section{Results}

The results from the morphological changes in the first and fourth erosive cycle ( four times $-90 \mathrm{sec}$. each) caused by the $0.1 \%$ citric acid and then treated with the appropriate agent for remineralisation, followed with a SEM - 500x zoom, are presented in the following pictures.

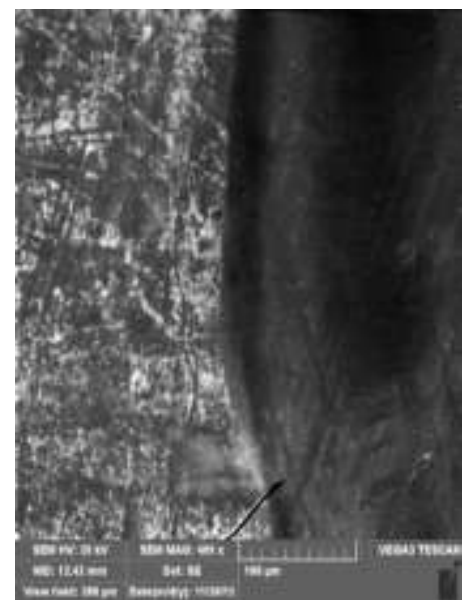

Picture 1

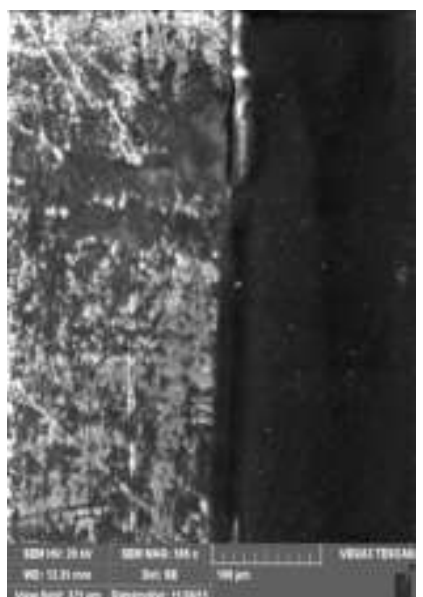

Picture 2

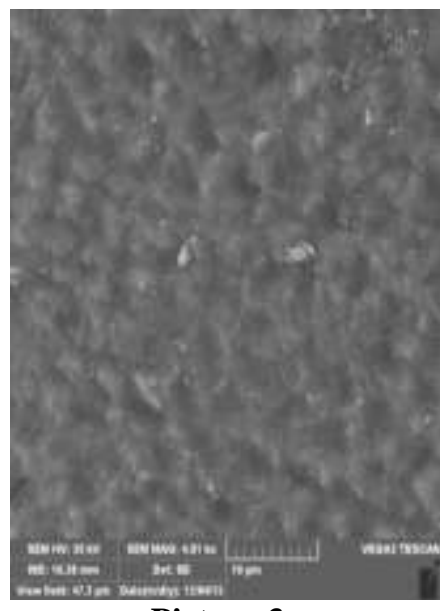

Picture 3 
Picture 1. SEM with zoom 500x, first day enamel sample with 4 erosive cycles, submerging in $0.1 \%$ citric acid in the duration of 90 seconds, on the test side (left) unlike the control side (right) we can clearly see the perikymata lines.

Picture 2. SEM with zoom 500x, first day enamel sample with 4 erosive cycles and two remineralisation cycles (after the first and the last erosive cycle) with Paradontax toothpaste, on the tested side (right) we can see deepening of the perikymata lines.

Picture 3. SEM with zoom 500x, forth day enamel sample with 4 erosive cycles and two remineralisation cycles (after the first and the last erosive cycle) with Paradontax toothpaste, on the tested side (right) we can see great damage on the structures in correlation to the previous cycles.

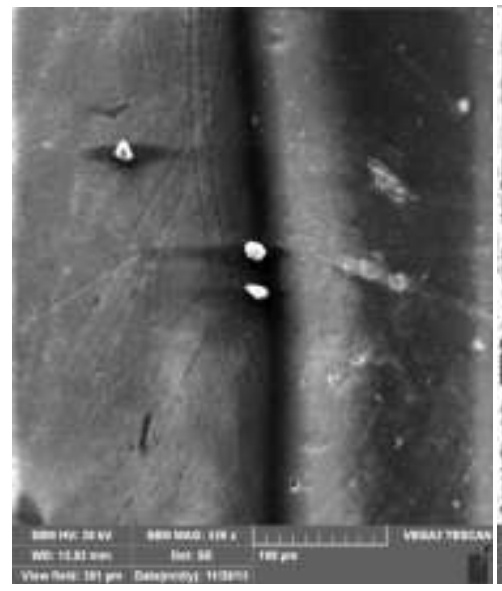

Picture 4

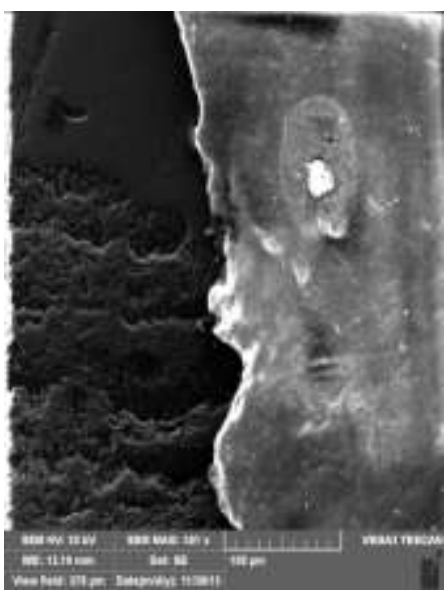

Picture 5

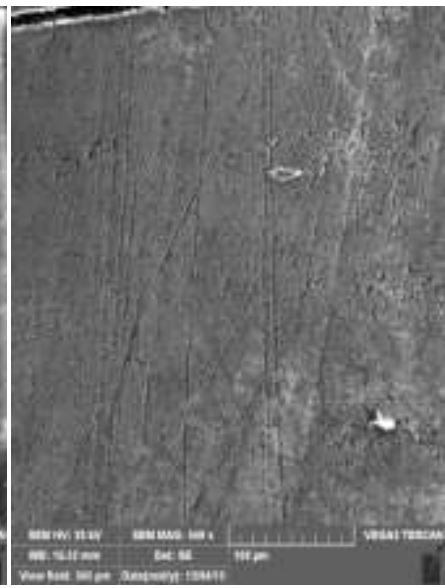

Picture 6

Picture 4. SEM with zoom 500x first day, enamel sample with 4 erosive cycles submerged in $0.1 \%$ citric acid in the duration of 90 seconds, on the test side (left) unlike the control side we can clearly see the perikymata lines.

Picture 5. SEM with zoom 500x, first day enamel sample with 4 erosive cycles and two remineralisation cycles (after the first and the last erosive cycle) with Crest toothpaste, on the tested side (left) we can see deepening of the perikymata lines.

Picture 6. SEM with zoom 500x, forth day enamel sample with 4 erosive cycles and two remineralisation cycles (after the first and the last erosive cycle) with Crest toothpaste, on the tested side (left) after the removal of the polish on the control side, besides the perkymata lines we cannot notice any other significant changes.

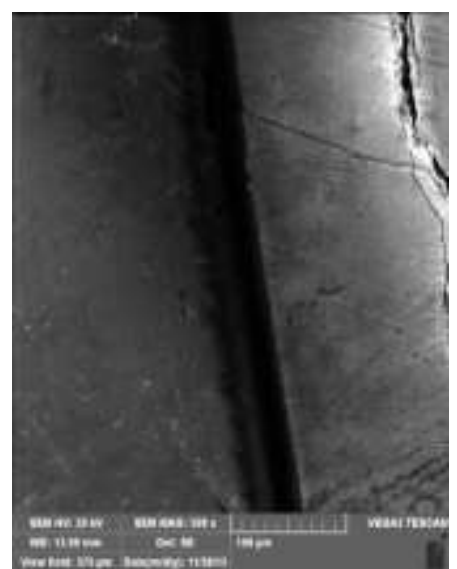

Picture 7

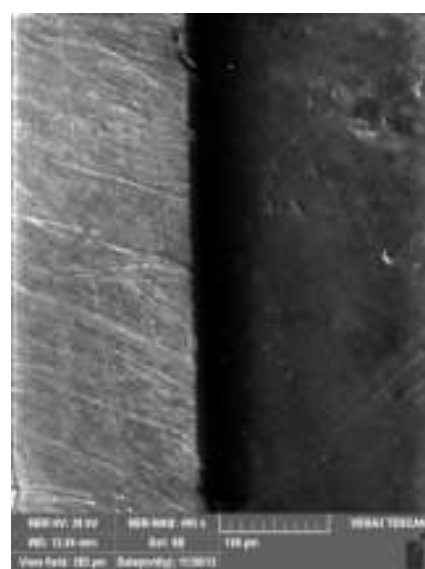

Picture 8

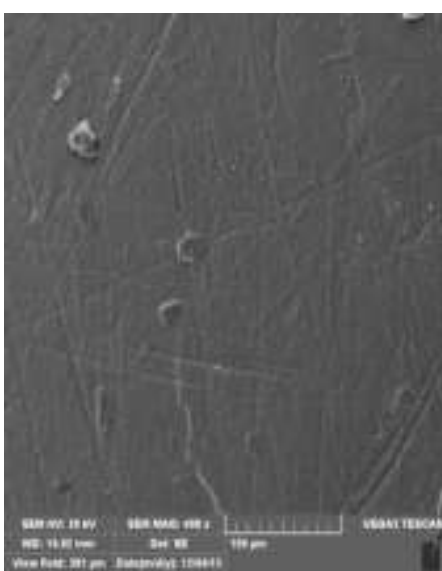

Picture 9

Picture 7 SEM with zoom 500x, first day, enamel sample with 4 erosive samples, submerged in $0,1 \%$ citric acid for 90 seconds, on the tested side (right) in correlation to the control side, we can clearly see the perikymata lines and fissures on the enamel. 
Picture 8. SEM with zoom 500x first day enamel sample with 4 erosive cycles and 2 remineralisation cycles (after the first and last erosive cycles ) with White Glo toothpaste, on the tested side (right) in correlation to the control side, we can see deepening of the perykimata lines.

Picture 9. SEM with zoom 500x, fourth day enamel sample with 4 erosive cycles and 2 remineralisation cycles (after the first and last erosive cycles) with White Glo toothpaste, on the tested side (left) we can see the perikymata lines more clearly, and the damage on the enamel in correlation to the control side after removal of the nail polish we can see a very little difference.

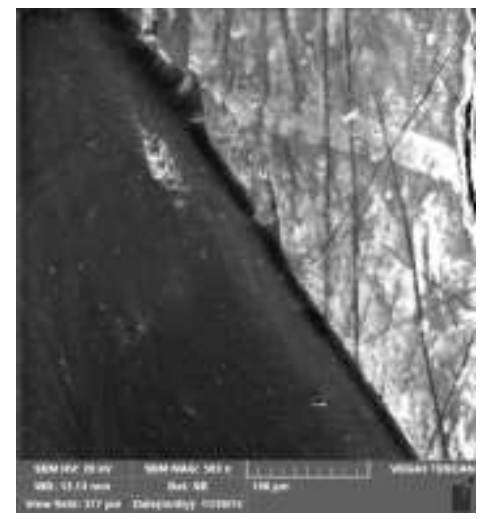

Picture 10

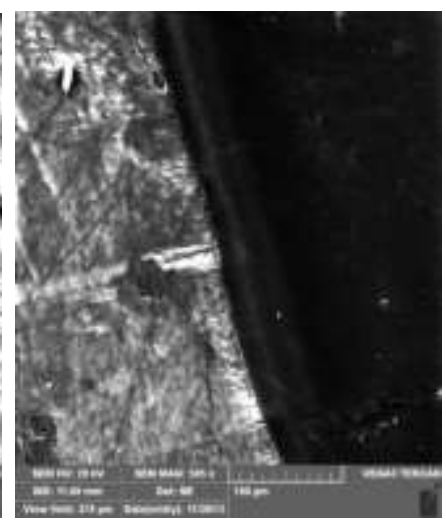

Picture 11

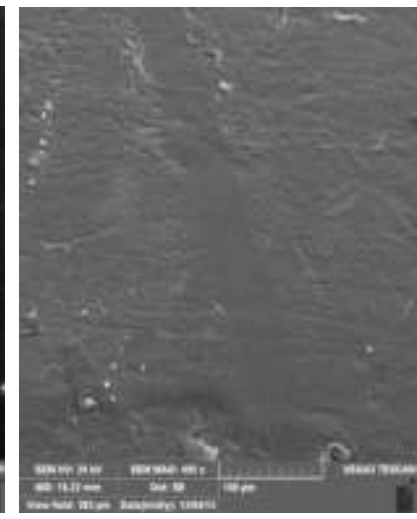

Picture 12

Picture 10. SEM with zoom 500x, first day enamel sample with 4 erosive cycles, submerged in $0,1 \%$ citric acid for 90 seconds, on the tested side (left) in correlation to the control side, we can clearly see the perikymata lines. Picture 11. SEM with zoom 500x, first day enamel sample with 4 erosive cycles and two remineralisation cycles (after the first and the last erosive cycles) with a Fluoride solution in correlation to the control side we can notice the perikymata lines.

Picture 12.SEM with zoom 200x, fourth day enamel sample with 4 erosive cycles and 2 remineralisation cycles ( after the first and the last erosive cycles ) with a Fluoride solution, on the tested side (right) we can see less perikymata lines and irregularities (furrows) on the enamel in correlation to the previous days without a greater difference in correlation to both sides.

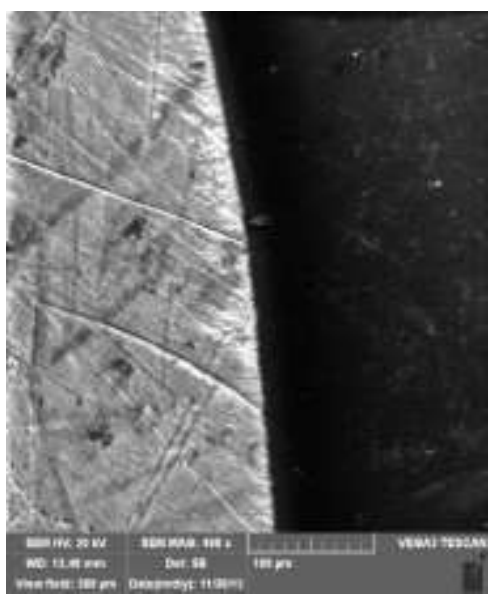

Picture 13

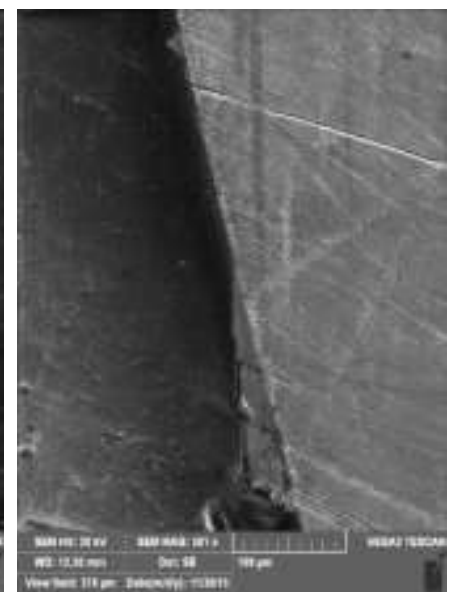

Picture 14

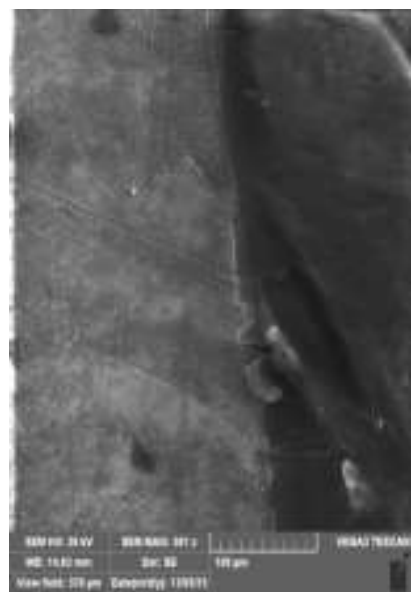

Picture 15

Picture 13.Picture 10. SEM with zoom 500x, first day enamel sample with 4 erosive cycles, submerged in $0,1 \%$ citric acid for 90 seconds, on the tested side (left) in correlation to the control side, we can clearly see the perikymata lines and other irregularities which probably occurred from the preparation phase in which the samples were cut.

Picture 14. SEM with zoom 500x, first day enamel sample with 4 erosive cycles and two remineralisation cycles (after the first and the last erosive cycles) with TiF4on the tested side (right) we can notice an exceptionally smooth enamel surface and the perikymata lines from the enamel and enamel prisms are less visible. 


\section{Discussion}

Throughout life, the teeth are exposed to a number of harmful effects, which more or less contribute to the occurrence of wearing and loss of morphological features. The morphological changes and the extent of the defects can significantly vary depending on the predominant etiological factor, the type of dentition and time of usage. ${ }^{16,17}$

During life the teeth are exposed to a great number of harmful effects, which more or less can lead to the occurance of loss of the morphological characteristics. The morphological changes and the level of defects can significantly differ from the main etiological factor, the type of teeth and the time of consumption. ${ }^{18}$

The dental erosions are conditions, characterized with the loss of the hard tooth tissues from non-carious multifactorial etiology which represents an irreversible process, which occurs as a results from chemical and mechanical factors, in which the bacteria are not included, and some of them are directly associated with traumatic factors. The morphology and the seriousness of the defects can significantly differ in correlation to the dominant etiological factor. ${ }^{19,20}$

The results from our study show that the erosive effect of the citric acid $(0,1 \%)$ which was used in our study on the enamel and dentin samples, and which were analyzed on a SEM microscope, which is one of the best methods for analyzing of the morphological changes, show that after the first erosive cycle, the remineralisation effect does not show significant morphological changes no matter the agent we used for remineralisation (Crest, Paradontax, WhitoGlo, TiF4, Fluoride Solution).

We want to accent that in the later part of the study after the fourth and fifth remineralisation cycle, we expected more significant changes in the samples which were examined with a SEM microscope and on which a more sophisticated methodologiy after Koater with steamed Nanogold particles was used.

Imfeld ${ }^{21}$ presumes that the high concentration of fluoride can promote the formation of an almost nonpermeable remineralized surface layer, from which the enamel pores are blocked and the ion trading activity of the surface of the enamel is decreased and at the end the remineralisation of the basic lesion which is located on a sub superficial level is blocked, but he advises that all of this should be proven with comprehensive studies. The results which we got from the enamel samples treated after the fourth day ( before this they were treated 3 days with erosive cycles by submerging in $0.1 \%$ citric acid for 90 seconds and with 2 remineralisation cycles after the first and last erosive cycles) show that the surface of the enamel that was treated with the Parodontax toothpaste which doesn't contain fluoride and the treatment with the Crest toothpaste and the White Glo toothpaste did not give significant changes in correlation to the protected part of the enamel which was used as a control, in other words we noticed changes on the experimental part of the enamel such as perikymata lines and furrows as a result of the treatment with the citric acid.

The enamel samples which underwent 4 different erosive cycles, after the fourth day, the samples which were treated with a Fluoride solution showed somewhat better results, when the prevention is taken into consideration, more precisely, although perikymata lines and furrows were present, they were less intense in correlation to the ones present the previous days and with a greater difference in correlation to the control side.

The results we got while using TiF4 show that his preventive effect on the eroded enamel was the most evident. On the surface of the eroded enamel we can notice a smooth surface which is very similar to the surface which was used as a control.

Comar and al. $^{22}$ studied the effect of the demineralised enamel with $0,1 \%$ citric acid, $\mathrm{pH} 2.5,30$ minutes, which were then treated with $4 \%$ TiF4 polish $(2,45 \%$ F-, pH 1,0), 5,42\% NaF polish, $(2,45 \% \mathrm{~F}-, \mathrm{pH}$ $5,0)$, and a placebo polish without fluorides, concluded that the used drugs were evenly effective in decreasing the progression of dental erosion, which is in correlation to the results which we got, in vitro. Similar results were seen by Castilho and col. ${ }^{23}$ which found that every day use of experimental toothpastes which have TiF4 and $\mathrm{NaF}$ decreases erosion on the dentin. Souza and col. ${ }^{24}$ analyzed the anti-erosive effects of the experimental solutions which have TiF4 and $\mathrm{NaF}$, and the best anti-erosive effect was seen in the experimental toothpaste with $0,0815 \% \mathrm{TiF}$ (99\% decrease of the dental enamel), then with SnCL2/NaF (78\%) and 0,049\% 0,042\% solution $\mathrm{TiF} 4+\mathrm{NaF}(41 \%)$. The authors concluded that the experimental solution which consists of a specific combination of $\mathrm{TiF} 4+\mathrm{NaF}$ has the ability to decrease the enamel erosion partially.

The quality of the dental protection and the contemporary achievements in the dental science strongly depend on the knowledge of the characteristics of the teeth and the basic principles and mechanisms which are involved in their interaction with the surrounding medium. The erosion of the teeth is a result of the interaction of the teeth with the erosive acids which more or less are present in the food and drinks which we digest daily. $25,26,27,28,29$

We would like to point out that the histopathological aspect of the erosive processes depend on the histological characteristics of the dental erosion, which probably differs from the one seen in dental caries, and this difference is seen in both enamel and dentin. Given the specific morphology of the erosion of the hard dental tissue, and the effects of the therapeutic strategies, the histological findings are important for the proper choice and use of methods for quantifying and use of proper prophylactic therapeutic procedures. 


\section{Conclusion}

The results from our study showed that the toothpastes which contain fluoride can inhibit the demineralisation of the dental enamel, especially when we take the Fluoride solution TiF4 into consideration. We suggest that there is a need for further clinical studies which would confirm the results but in more complex conditions which exist in the oral cavity.

\section{References}

[1]. McCracken and S. J. O'Neal, "Dental erosion and aspirin headache powders: a clinical report," Journal of Prosthodontics, vol. 9, no. 2, pp. 95-98, 2000.

[2]. Ganss C, Lussi A. Diagnosis of Erosive Tooth Wear. In: Lussi A.Dental Erosion form Diagnosis to therapy. Basel; Karger 2006:p 32-43.

[3]. Al-Dlaigan Y H, Shaw L, Smith A. Dental erosion in a group of British 14 year old school children. Part I: prevalence and influence of differing socioeconomic backgrounds. Br Dent J 2001; 190: 145-49.

[4]. Featherstone JDB, Lussi A: Understanding the chemistry of dental erosion; in Lussi A (ed): Dental Erosion: From Diagnosis to Therapy. Monogr Oral Sci. Basel, Karger, 2006, vol 20, pp 66-76

[5]. Graubart J, Gedalia I, Pisanti S. Effects of fluoride pretreatment in vitro on human teeth exposed to citrus juice.Journal Dental Research 1972;51:1677-80.

[6]. Bartlett D, Dugmore C. Pathological or physiological erosion--is there a relationship to age? Clin Oral Investig. 2008;12 Suppl 1:S27-31. :. ABSTRACT :.

[7]. Amaechi BT, Higham SM, Edgar WM. Factors influencing the development of dental erosion in vitro: enamel type, temperature and exposure time. J Oral Rehabil. 1999;26(8):624-30.

[8]. Shipley S, Taylor K, Mitchell W.Identifying causes of dental erosion. Gen Dent. 2005;Jan- Feb:73-75.

[9]. Murray, JJ; Rugg-Gunn, AJ; Jenkins GN - editors. Fluorides in caries prevention. 3 rd ed. Oxford: Wright; 1991.

[10]. Featherstone JD. The continuum of dental caries--evidence for a dynamic disease process. J Dent Res. $2004 ; 83$ Spec No C:C39- 42.

[11]. Al-Mullahi AM, Toumba KJ. Effect of slow-release fluoride devices and casein phosphopeptide/amorphous calcium phosphate nanocomplexes on enamel remineralization in vitro. Caries Res. 2010;44(4):364-71.

[12]. Marinho VC, Higgins JP, Logan S, Sheiham A. Fluoride gels for preventing dental caries in children and adolescents. Cochrane Database Syst Rev. 2002;(2):CD002280.

[13]. Stookey GK, Beiswanger BB. Topical fluoride therapy. In: Harris NO, Christen AG, eds. Primary preventive dentistry. 4th ed. Stamford, CT: Appleton \& Lang, 1995:193--233.

[14]. Horowitz HS, Ismail AI. Topical fluorides in caries prevention. In: Fejerskov O, Ekstrand J, Burt BA, eds. Fluorides in dentistry. 2nd ed. Copenhagen: Munksgaard, 1996:311--27.

[15]. Wagener DK, Nourjah P, Horowitz AM. Trends in childhood use of dental care products containing fluoride: United States, 1983-89. Hyattsville, MD: U.S. Department of Health and Human Services, Public Health Service, CDC, 1992. (Advanced data from vital health statistics; no. 219).

[16]. Smith BGN, Robb ND. The prevalence of tooth wear in 1007 dental patients. J Oral Rehb 1999; 23: 232-39.

[17]. Al-Zarea BK. Tooth surface loss and associated risk factors in northern saudi arabia. ISRN Dent. 2012;2012:161565.

[18]. Larsen MJ: Chemical events during tooth dissolution. J Dent Res 1990;69(spec No):575-580.iangprach T, Hengtrakool C, Kukiattrakoon B, Kedjarune-Leggat U. The effect of salivary factors on dental erosion in various age groups and tooth surfaces. J Am Dent Assoc. 2009 Sep;140(9):1137-43.

[19]. Kaifu Y, Kasai K, Townsend GC, Richards LC: Tooth wear and the 'design' of the human dentition: a perspective from evolutionary medicine. Am J Phys Anthropol 2003;(suppl 37):47-61

[20]. Brand HS, Tjoe Fat GM, Veerman ECI. The effects of saliva on the erosive potential of three different wines. Austral Dent J. 2009 Sep;54(3):228-32

[21]. Imfeld T. Prevention of progression of dental erosion by professional and individual prophylactic measures. European Journal Oral Sciences 1996;104:215-20.

[22]. Comar LP, Cardoso Cde A, Charone S, Grizzo LT, Buzalaf MA, Magalhães AC.TiF4 and NaF varnishes as anti-erosive agents on enamel and dentin erosion progression in vitro. J Appl Oral Sci. 2015 Jan-Feb;23(1):14-8

[23]. Castilho AR, Salomão PM, Buzalaf MA, Magalhães ACProtective effect of experimental mouthrinses containing NaF and TiF4 on dentin erosive loss in vitro. Appl Oral Sci. 2015 Oct;23(5):486-90

[24]. Souza BM, Lima LL, Comar LP, Buzalaf MA, Magalhães ACEffect of experimental mouthrinses containing the combination of $\mathrm{NaF}$ and TiF4 on enamel erosive wear in vitro. Arch Oral Biol. 2014 Jun;59(6):621-4.

[25]. Larsen MJ: Chemical events during tooth dissolution. J Dent Res 1990;69(spec No):575-580.

[26]. 2 Lussi A, Jaeggi T, Jaeggi-Schärer S: Prediction of the erosive potential of some beverages. Caries Res 1995;29:349-354.

[27]. Lussi A, Portmann P, Burhop B: Erosion on abraded dental hard tissues by acid lozenges: an in situ study. Clin Oral Invest 1997;1:191-194.

[28]. Maupome G, Diez-de-Bonilla J, Torres-Villasenor G, Andrade-Delgado LC, Castano VM: In vitro quantitative assessment of enamel microhardness after exposure to eroding immersion in a cola drink. Caries Res 1998;32:148-153.

[29]. Smith BG, Knight JK: An index for measuring the wear of teeth. Br Dent J 1984;156:435-438. 